\title{
Resilience assessment
}

\author{
Allyson Quinlan, ${ }^{1}$ My Sellberg ${ }^{2}$ and Arthur Perrotton ${ }^{2}$ \\ ${ }^{1}$ RESILIENCE ALLIANCE, OTTAWA, CANADA \\ ${ }^{2}$ STOCKHOLM RESILIENCE CENTRE, STOCKHOLM UNIVERSITY, STOCKHOLM, SWEDEN
}

\section{Key methods discussed in this chapter}

Wayfinder, RAPTA, Resilience Assessment Workbook for Practitioners 2.0, STRESS, operationalising systemic resilience

\section{Connections to other chapters}

Resilience assessment is an umbrella process within which a wide range of tools and methods can be used. During the first stages of the assessment, systems scoping (Chapter 5) will be performed, commonly also interviews with key informants (Chapter 7) and participatory data collection (Chapter 8), such as timelines and historical profiling. Resilience assessment often benefits from reviewing previous collections of ecological field data (Chapter 6). The more technical part of the assessment includes systems analysis, such as expert modelling (Chapter 16), network analysis (Chapter 23), causal loop diagrams or other dynamical systems modelling (Chapter 26), and state-and-transition modelling (Chapter 27). The entire participatory process will draw on elements from different co-production methods, including facilitated dialogues and change labs (Chapter 9), scenario development (Chapter 11), and participatory modelling and planning (Chapter 13), particularly adaptive environmental management. Resilience assessment could also include action research (Chapter 15), futures analysis (Chapter 10) and qualitative content analysis (Chapter 19).

\section{Introduction}

Resilience assessment is a strategic approach grounded in theory that integrates multiple methods relevant to social-ecological systems (SES) research, in order to better understand the dynamics of complex SES and design strategic interventions. Although primarily designed for applying resilience theory in practice, the approach is often used as a research method. While the core technical component focuses on analysing system dynamics, 


\begin{tabular}{|c|c|}
\hline \multicolumn{2}{|c|}{ SUMMARY TABLE: RESILIENCE ASSESSMENT } \\
\hline DISCIPLINARY BACKGROUND & KNOWLEDGE TYPE \\
\hline $\begin{array}{l}\text { The methods in this chapter are derived } \\
\text { from or have most commonly been used in: } \\
\text { Ecology, Sociology, Environmental } \\
\text { Science, Human Geography, } \\
\text { Development Studies }\end{array}$ & $\begin{array}{l}\text { The methods in this chapter are primarily } \\
\text { used to generate the following types of } \\
\text { knowledge: } \\
\text { - Descriptive } \\
\text { - Exploratory }\end{array}$ \\
\hline RESEARCH APPROACH & PURPOSE OF METHOD \\
\hline $\begin{array}{l}\text { The methods in this chapter originate } \\
\text { from or most commonly adopt the } \\
\text { following research approaches: } \\
\text { - Interpretive/subjective } \\
\text { - Collaborative/process }\end{array}$ & $\begin{array}{l}\text { The most common purposes of using the } \\
\text { methods in this chapter are: } \\
\text { - Data collection/generation } \\
\text { - System understanding } \\
\text { - Stakeholder engagement and } \\
\text { co-production } \\
\text { - Policy/decision support }\end{array}$ \\
\hline TEMPORAL DIMENSION & SYSTEMIC FEATURES AND PROCESSES \\
\hline $\begin{array}{l}\text { The methods in this chapter are most } \\
\text { commonly applied to the following } \\
\text { temporal dimensions: } \\
\text { - Present (typically within the last } \\
5-10 \text { years) } \\
\text { - Recent past (post-1700s) } \\
\text { - Future }\end{array}$ & $\begin{array}{l}\text { While most methods can do many } \\
\text { things, the methods in this chapter are } \\
\text { particularly good (i.e. go-to methods) for } \\
\text { addressing the following: } \\
\text { - SES components and linkages } \\
\text { - Multiple scales and levels or } \\
\text { cross-level interactions }\end{array}$ \\
\hline SPATIAL DIMENSION & - Regime shifts \\
\hline $\begin{array}{l}\text { The methods in this chapter are primarily } \\
\text { either or both: } \\
\text { - Non-spatial } \\
\text { - Explicitly spatial }\end{array}$ & $\begin{array}{l}\text { - Social learning } \\
\text { - Collective action and } \\
\text { collaborative governance } \\
\text { - Exploring uncertainty }\end{array}$ \\
\hline $\begin{array}{l}\text { The methods in this chapter are most } \\
\text { commonly applied at the following } \\
\text { spatial scales: } \\
\text { - Local } \\
\text { - Regional (provincial/state } \\
\text { to continental) } \\
\text { - Multiple places/sites around the world }\end{array}$ & \\
\hline
\end{tabular}


resilience assessment increasingly emphasises the process itself, including strategic engagement, knowledge co-creation and leveraging existing opportunities to help ensure actionable outcomes.

Resilience assessment can be applied in any SES (e.g. rural villages, cities, coastal fisheries, working landscapes) where people depend upon, shape and respond to their environment. Central to resilience assessment is the development of a conceptual model that integrates social and ecological variables and explicitly considers external drivers and system feedbacks (Walker and Salt 2012). The approach assumes an integrated humans-innature worldview that encourages multiple types of knowledge and evidence. While a key objective of most assessments is to better understand SES dynamics in order to influence change in the system, it also accepts that this knowledge will always be partial in complex adaptive systems.

The early framework developed by Walker and colleagues (2002) ('A working hypothesis for a participatory approach to applying resilience thinking') introduced a set of methods to help researchers and practitioners view natural resource issues from a systems perspective. These methods included describing the system and historical timelines, mapping external drivers and using future scenarios. While the methods themselves were not new, Walker and colleagues combined them in a framework for the purpose of understanding resilience in SES. Resilience was defined as the amount of change a system can undergo and still retain its structure and function, and its capacity for self-organisation, adaptation and learning (Walker et al. 2002). Building on these core elements, the Resilience Alliance (RA) (2010) developed a practitioner's workbook, integrating concepts such as system thresholds, interactions across scales, social networks and adaptive governance. Most of the resilience assessment approaches available today that are designed to address SES problems and questions can be traced to these original publications.

While early applications of resilience assessment tended to focus on ecological dynamics, over time greater attention was paid to human dimensions and fully integrated SES dynamics (Anderies, Walker, and Kinzig 2006; Walker and Salt 2012). This shift is also reflected in changing definitions of resilience, which more recently has been defined as the capacity of an SES to persist in the face of disturbance and change, while continuing to adapt and develop along a pathway or transform and navigate new pathways in order to sustain human well-being (Biggs, Schlüter, and Schoon 2015; Folke 2016). Increasingly, resilience thinking takes into account and integrates notions of governance systems, ecosystem services and human well-being, adaptive capacity and transformation (Olsson, Folke, and Hughes 2008; Daw et al. 2015; Sellberg et al. 2018b). Engaging with complexity, a core concept of socialecological resilience thinking (Preiser et al. 2018) is increasingly seen as key to understanding and engaging with SES dynamics. As social-ecological research continues to advance, many new analytical methods, both qualitative and quantitative, are likely to become part of the resilience assessment toolkit, just as the process itself is becoming more of a continuous practice involving reflection and reiteration.

Resilience assessment approaches are now being developed by a range of organisations working in a variety of contexts, including coastal, urban and rural development, conservation and climate change, to name a few. This growing abundance of resilience assessment guides and tools (ODI 2016; Sharifi 2016; Douxchamps et al. 2017) highlights the many different ways in which resilience is conceptualised. However, only a relatively small number of these guides and tools align with an SES framing. In this chapter, we focus on a select few guides that are based on social-ecological perspectives and that engage with complexity. 


\section{SES problems and questions}

Resilience assessment broadly addresses questions about the capacity of an SES to cope with and respond to change. In the Anthropocene, people and nature increasingly face complex, wicked problems that demand coordinated actions across multiple scales (Steffen et al. 2011). Often there are no simple solutions since actions to improve the conditions and resources for one group might negatively affect another (Enfors-Kautsky et al. 2018). These types of challenges, which span domains and interact across scales, have raised interest in complexity-based approaches to better navigate change while moving towards more desirable futures (Sellberg et al. 2018a). Within the broad framing of just and sustainable futures, resilience assessment is an adaptable approach that employs a variety of social-ecological methods to address multiple issues that suit the context. Each assessment identifies as its focus one or more issues relevant to the particular SES.

The types of questions that resilience assessments generally deal with include:

- Understanding the resilience of an SES, how it has changed over time and what factors build or erode it; resilience assessment usually addresses both resilience to specific changes and potential shifts in a system state, as well as general resilience to unknown change

- Exploring strategies and actions for an SES to continue to deliver important ecosystem services to people in the face of change; these strategies can include buffering change, but also adapting and transforming in response to change

- Exploring how governance and management of an SES can be improved by taking more of the inherent system complexity and dynamics into account; the assumption is that this will better align the governance system with the underlying social-ecological processes and also make it more effective

In practice, these three areas of exploration might be partly overlapping and one resilience assessment could cover all of them. Below are examples of specific questions that resilience assessments have dealt with.

- How has resilience of an SES changed over time? (e.g. understanding how the resilience of a Coastal Pacific herring fishery changed during different management eras (Salomon et al. 2019))

- What factors build or erode resilience? (e.g. comparing cases of resilience and transformation across the Arctic region (Huitric, Peterson, and Rocha 2016))

- How can we increase the resilience of important ecosystem services in the face of future changes? (e.g. exploring strategies for building resilience of food systems in Eskilstuna Municipality in Sweden (Sellberg, Wilkinson, and Peterson 2015))

- How can we shift the system to a trajectory where important ecosystem services are more resilient? (e.g. exploring how the Telecho community in Ethiopia can transition to pathways to a more food-secure system (Maru et al. 2017))

- How can we manage an SES in a way that takes more of its complexity into account? (e.g. co-producing knowledge on multiple ecosystem services in the Helgea watershed, the synergies and trade-offs between them and potential positive future scenarios (Malmborg 2019)) 
- How can governance of an SES take more of the social-ecological connections and dynamics of change into account? (e.g. understanding the social and economic dimensions of natural resource management issues and identifying thresholds of potential concern in Australian natural resource management (Sellberg et al. 2018b))

- How can we design development interventions that address the systemic causes of problems, are more effective and have sustained benefits? (Maru et al. 2017)

\section{Brief description of key methods}

A small number of resilience assessment guides explicitly engage with the complex nature of SES. These approaches offer ways of exploring social-ecological dynamics and developing strategies to influence how a system might adapt or transform in the face of change. They also offer practical tools grounded in theory that can help researchers and others to assess and influence the resilience of complex adaptive systems (Sellberg et al. 2018a). While there are many other resilience assessment guides available that have been developed for a variety of purposes, the approaches included in Table 14.1 are designed to assess resilience specifically through a social-ecological lens.

Table 14.1 Summary of key approaches used in resilience assessment

\begin{tabular}{|c|c|c|}
\hline Approach & Description & References \\
\hline Wayfinder & $\begin{array}{l}\text { Wayfinder is a resilience guide for navigating } \\
\text { towards sustainable futures. It is a process guide } \\
\text { used for resilience assessment, planning and } \\
\text { action in SES. It describes a process for engaging } \\
\text { stakeholders at multiple levels, co-creating } \\
\text { knowledge and exploring system dynamics (e.g. } \\
\text { feedbacks, thresholds, cross-scale interactions) } \\
\text { and social-ecological dilemmas (e.g. ecosystem } \\
\text { service trade-offs). It includes tools for developing } \\
\text { strategic actions and deciding when to build } \\
\text { resilience and when to adapt or transform. } \\
\text { Wayfinder also offers practical guidance and an } \\
\text { online toolkit with ready-to-use activity sheets. }\end{array}$ & $\begin{array}{l}\text { Key introductory text } \\
\text { Enfors-Kautsky et al. } 2018 \\
\text { Applications to SES } \\
\text { Goffner, Sinare, and Gordon } \\
2019 ; \\
\text { Perrotton, Ka, and Goffner } \\
2019\end{array}$ \\
\hline $\begin{array}{l}\text { Resilience, } \\
\text { Adaptation } \\
\text { Pathways and } \\
\text { Transformation } \\
\text { Assessment }\end{array}$ & $\begin{array}{l}\text { The Resilience, Adaptation Pathways and } \\
\text { Transformation Assessment (RAPTA) framework } \\
\text { is a guide to developing and implementing } \\
\text { interventions for sustainable development. } \\
\text { It includes technical components of system } \\
\text { assessment (feedbacks, thresholds, cross-scale } \\
\text { interaction) and guidance on filtering options } \\
\text { and creating pathways for change. It has been } \\
\text { designed to work with project cycles and to } \\
\text { enhance or work with existing theory of change } \\
\text { methods. }\end{array}$ & $\begin{array}{l}\text { Key introductory text } \\
\text { O'Connell et al. } 2016 \\
\text { Applications to SES } \\
\text { Maru et al. } 2017 ; \\
\text { Cowie et al. } 2019\end{array}$ \\
\hline
\end{tabular}

(Continued) 
Allyson Quinlan et al.

Table 14.1 (Continued)

\begin{tabular}{|c|c|c|}
\hline Approach & Description & References \\
\hline $\begin{array}{l}\text { Resilience } \\
\text { Assessment } \\
\text { Workbook for } \\
\text { Practitioners } 2.0\end{array}$ & $\begin{array}{l}\text { The Resilience Assessment Workbook presents a } \\
\text { five-phase approach to assessing the resilience of } \\
\text { SES. This approach involves defining the system, } \\
\text { understanding system dynamics, identifying key } \\
\text { relationships, exploring system governance and } \\
\text { acting on the assessment. }\end{array}$ & $\begin{array}{l}\text { Key introductory texts } \\
\text { Walker et al. 2009; } \\
\text { Resilience Alliance } 2010 \\
\text { Applications to SES } \\
\text { Haider, Quinlan, and Peterson } \\
2012 ; \\
\text { Walker and Salt 2012; } \\
\text { Wilkinson 2012; } \\
\text { Sellberg, Wilkinson, and } \\
\text { Peterson 2015; } \\
\text { Sellberg et al. 2018b }\end{array}$ \\
\hline STRESS & $\begin{array}{l}\text { Strategic Resilience Assessment (STRESS) is a } \\
\text { learning process for resilience planning that } \\
\text { includes a communications plan, a work plan } \\
\text { and field-team training. It includes practical } \\
\text { guidance on the time and skills required for the } \\
\text { assessment, which works towards developing } \\
\text { a resilience-focused theory of change. STRESS } \\
\text { combines resilience concepts with vulnerability } \\
\text { assessment (e.g. developing vulnerability } \\
\text { profiles, identifying vulnerable groups). }\end{array}$ & $\begin{array}{l}\text { Key introductory text } \\
\text { Levine, Vaughan, and } \\
\text { Nicholson } 2017 \\
\text { Applications to SES } \\
\text { Mercy Corps } 2018\end{array}$ \\
\hline $\begin{array}{l}\text { Operationalising } \\
\text { systemic resilience }\end{array}$ & $\begin{array}{l}\text { Operationalising systemic resilience is a } \\
\text { multi-stakeholder process to build community } \\
\text { resilience. The framework is derived from a } \\
\text { critical analysis of resilience thinking, systems } \\
\text { thinking, community operational research } \\
\text { and development studies. Phases in the } \\
\text { process include critiquing system boundaries, } \\
\text { visioning (negotiating desirable change } \\
\text { 'for whom'), setting time frames through } \\
\text { asset mapping and back-casting, scenario } \\
\text { development to probe uncertainties, locally } \\
\text { driven implementation, evaluation learning } \\
\text { and re-evaluation. }\end{array}$ & $\begin{array}{l}\text { Key introductory text } \\
\text { Helfgott } 2018 \\
\text { Applications to SES } \\
\text { No known applications }\end{array}$ \\
\hline
\end{tabular}

\section{Limitations}

Resilience assessment is a practical, hands-on, transdisciplinary and collaborative approach for exploring critical issues in SES. There are a number of limitations or challenges, many of which also apply to other participatory knowledge co-production processes.

At a conceptual level, a complex adaptive systems mindset is key to resilience assessment, but this takes time to develop and often is in direct contrast to prevailing views. When resilience assessment was used by catchment management authorities in Australia, the practitioners often experienced a clash with existing mainstream approaches to natural resource management that assume linear cause-and-effect relationships (Sellberg et al. 2018b). By contrast, the resilience assessment approach highlights real-world complexity and does not sit neatly within one sector; rather, it acknowledges that outcomes are uncertain, which can 
sometimes be very challenging. Cross-scale interactions can also appear abstract or too far removed from the system and may be difficult to evaluate, but conceptual models are helpful in this regard (e.g. see Walker et al. 2009).

At a practical level, the approach is process intensive, requiring significant time and resource investments and a commitment to revisiting past steps and challenging assumptions as new knowledge and understanding is gained. As with most transdisciplinary and collaborative approaches, resilience assessment requires time for building relationships and trust and embedding or anchoring the process in an organisation or community. In two Swedish cases, for example, the assessments were mainly side projects to the normal operations, carried forward by engaged key individuals (Sellberg, Wilkinson, and Peterson 2015; Sellberg et al. 2017). As seen in some cases in Australia, where resilience assessment has been used the longest, it takes several years to really embed the approach in an organisation because it requires changes in the organisational culture, structure and processes (Sellberg et al. 2018b). Some have suggested simpler and faster approaches to assessing resilience, but ultimately there are no shortcuts to enabling systemic change, which inevitably involves a long-term commitment (Enfors-Kautsky et al. 2018).

As an ongoing method for understanding system dynamics, resilience assessment is incompatible with short-term project frames that are common in programmes that expect predetermined outcomes according to a set schedule. This points to an ethical consideration of not starting a resilience assessment where there is no possibility of a long-term commitment and follow-through. Resilience assessment has been ongoing in parts of Australia for well over a decade. In Tajikistan, external experts conducted a resilience assessment over a one-year period, but in partnership with an NGO with a long-term engagement in the area (Sellberg et al. 2018a). Capacity building, as part of the Tajikistan project, also ensured that the NGO could continue using and adapting the resilience assessment approach in their operations.

\section{Resource implications}

Resilience assessment as described in this chapter is a learning process that requires both a long-term commitment and sufficient resources, including skilled facilitation and people who are trained to guide a participatory process. Resilience assessments also draw on existing sources of data, e.g. regarding different environmental aspects. The quality of and access to these data will determine the depth and quality of the assessment.

The leader or team leading a resilience assessment needs inter- and transdisciplinary skills, since they need to integrate many different types of knowledge and sources of information, e.g. qualitative and quantitative data from natural and social science, as well as practical and experiential knowledge with scientific knowledge. If diverse participants are engaged in the process of assessing resilience and analysing systems, they also need skills that can be translated to ground complex concepts in real-world examples that are relevant to the context. Established networks and relationships with key stakeholders and non-academic partners are not prerequisites but can greatly facilitate the process and decrease the time of preparation.

The assessment leaders or teams also need to be trained in resilience and systems thinking. They also need a complex adaptive systems mindset and the pedagogical skills to teach this mindset to other core people involved in the resilience assessment, if necessary. Additional skills in particular methods and tools, such as scenario development (Chapter 11) or dynamical systems modelling (Chapter 26), will be useful, without getting too attached to any one tool. The case will determine which tool will be useful and it is recommended to have a variety of tools at one's disposal. 


\section{Case study 14.1: Collectively redefining a better future in Ranérou-Ferlo, Senegal}

Nearly 60 years after independence, rural populations living in the Ferlo, i.e. the northern Sahelian part of Senegal, continue to face immense development challenges. The majority of people living in the region are Fulani pastoralists who rely on extensive livestock herding. Vulnerability persists in the region, despite decades of development initiatives by the Senegalese government and international organisations leading to increased access to health care, education and water. Among the key issues are climate variability (e.g. Herman et al. 2018), malnutrition (e.g. Lazzaroni and Wagner 2016), land degradation (e.g. Hermann, Aziz Diouf, and Sall 2019), and persistent tensions among local actors over the use of pastoral resources. Researchers from the French government-funded Future Sahel Project, in collaboration with the Senegalese Great Green Wall Agency, conducted an 18-month-long participatory process with the goal of co-creating an innovative strategic development plan for the district of Ranérou-Ferlo.

Following the Wayfinder guide (Enfors-Kautsky et al. 2018), the process began by identifying who to engage and doing an initial system exploration. Two coalitions were quickly established: (a) a 'national coalition' (Dakar) involving managers of the national Great Green Wall Agency, and (b) a 'local coalition' (Ranérou) involving the district administrator and the head of the local office of the Directorate of Water, Forestry, Hunting and Soil Conservation. Together with these coalitions, researchers mobilised local citizens to form a multi-stakeholder working group. This group identified a set of local aspirations for development, along with existing constraints that were preventing the realisation of these aspirations. These included, for instance, the general lack of collective action, the lack of accountability of governance actors, the spread of uncontrolled settlements, and prejudices and misconceptions about Fulani herders. The next step used a systems lens to identify key leverage points that were revealed in conceptual models drawn by participants, as well as the networks of interactions between aspirations for the system and constraints.

In the final step of the process, four action strategies were collectively designed. Each strategy revolved around a set of linked aspirations and proposed actions to trigger specific changes in the district of Ranérou-Ferlo in order to reach these aspirations, while bringing the district closer to a more resilient path (future-sahel.blogspot.com).

The resilience assessment process: (a) confirmed the pressing need for improvement of social-ecological conditions in the area, (b) helped researchers and stakeholders to collectively identify development priorities and create strategies that target key leverage points, and (c) along with local actors highlighted the importance of social-oriented development actions in environmental protection. A strategic plan was distributed to all governance and development actors involved in the process. The development planning document included explanations of key concepts in the theoretical framework of the Wayfinder approach, and provided full descriptions of the strategies that had been co-designed with local actors.

The Wayfinder process conducted in Ranérou (Figure 14.1) integrated three groups of actors working at local to national levels. Their respective activities contributed towards developing strategies for change. At a local scale, results of workshops with the multi-stakeholder group were presented by the research team and discussed 
with the local coalition. To enable the implementation of the strategies, leaders of the Senagalese Great Green Wall Agency were involved through the national coalition.

Many of the challenges encountered with this case study are common to participatory processes in rural areas, including language barriers and the low literacy rates of workshop participants. These were overcome by including Senegalese researchers who could speak Fulani and using drawings and other visual aids during workshops. To address power imbalances among local actors, stakeholder groups met separately first to ensure the inclusion of marginalised voices. Locally relevant metaphors were used to help explain otherwise abstract theoretical concepts that do not always translate well.

The Wayfinder resilience assessment approach was well suited to the objectives and context of research in the Ranérou-Ferlo SES. Beyond the key insights gained regarding local system dynamics, the coalitions helped to maintain a focus on realistic and relevant development strategies, which could be supported and eventually implemented by governance and development actors. Simultaneously, trust among coalition members enabled dialogue about alternative land management options that challenged existing beliefs and habits and opened up new possibilities. Importantly, the involvement of governance actors in the coalitions facilitated uptake of the results in their networks and within the organisations that will implement the development strategies.

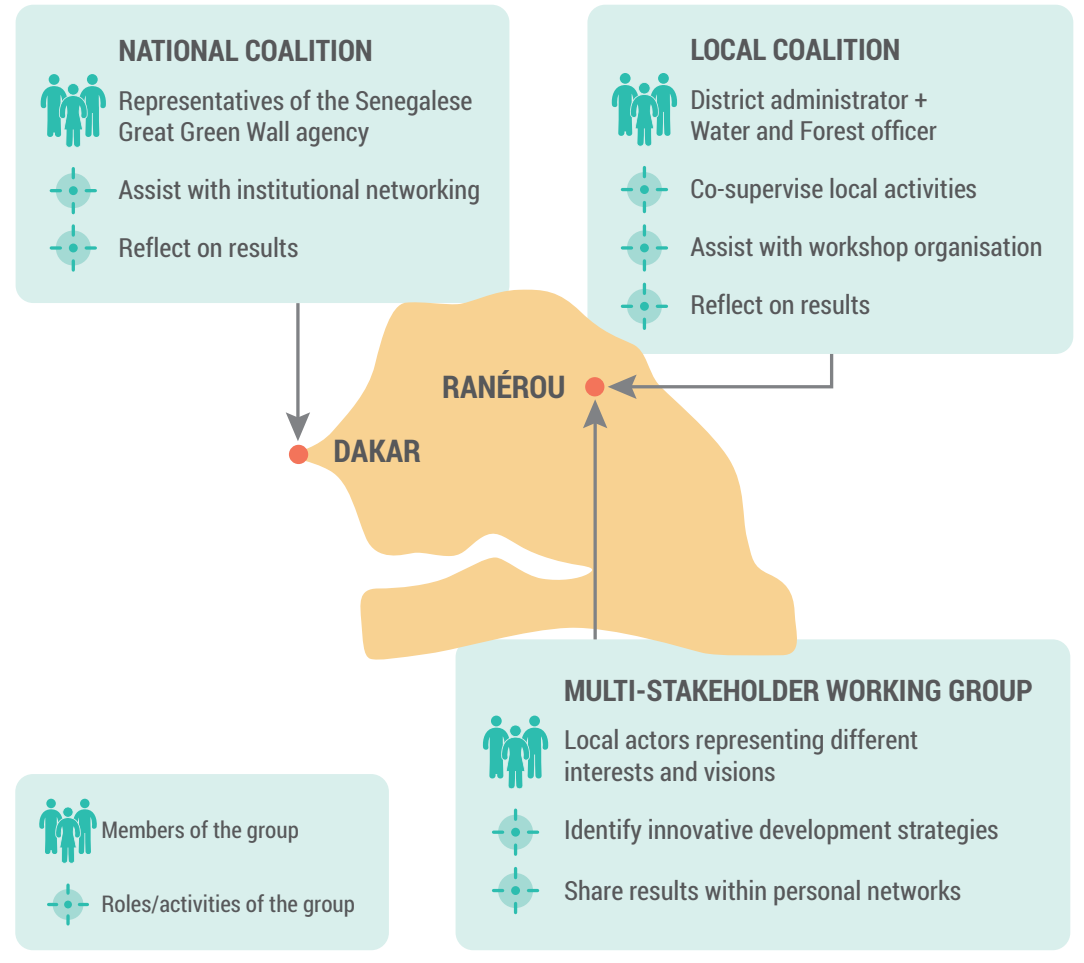

Figure 14.1 A multi-level process framework for resilience assessment in Ranérou, Senegal (@ Arthur Perrotton) 


\section{New directions}

While resilience assessment has traditionally been oriented towards natural resource management and planning processes, it is increasingly being used to inform development programming (Haider, Quinlan, and Peterson 2012; Pollard, Biggs, and Du Toit 2014; Maru et al. 2017; Enfors-Kautsky et al. 2018). A growing number of guides have been designed to streamline the assessment with project cycles and have integrated traditional development methods such as theory of change, capitals approaches and livelihood analysis (OECD 2014; O'Connell et al. 2016; Levine, Vaughn, and Nicholson 2017; UNDP 2017). The intersection of resilience and development practice has the potential to be a source for interdisciplinary innovation by combining and creating new methods. The recently developed Wayfinder approach offers a new framing of change narratives that is informed by theory of change and social innovation, and combines agency, opportunity context and strategic leverage points (Enfors-Kautsky et al. 2018). A number of rapid resilience assessment approaches are also being developed, mostly using quantitative methods, to suit a variety of project objectives (Salomon et al. 2019).

Resilience assessment is increasingly used in urban contexts, as resilience is a key issue for many cities facing extreme weather events, a lack of water and other disruptions (Elmqvist et al. 2019). A recent study assessed the resilience of ecosystem services to climate change and urban growth in southern Stockholm, Sweden, for example (justurbangreen.com/web/ en/startpage/enable). This project emphasised spatial aspects of resilience, which are relevant for city planning.

Several recent guides have placed more emphasis on transformation to sustainable and just pathways, in line with the global goals of sustainable development (O'Connell et al. 2016; Enfors-Kautsky et al. 2018). This direction may influence future applications of resilience assessment to focus more on questions of how a system can shift to sustainable pathways, or build transformative capacity.

\section{Key readings}

Enfors-Kautsky, E., L. Järnberg, A. Quinlan, and P. Ryan. 2018. 'Wayfinder: A Resilience Guide for Navigating Towards Sustainable Futures.' GRAID programme, Stockholm Resilience Centre. www.wayfinder.earth.

Helfgott, A. 2018. 'Operationalising Systemic Resilience.' European Journal of Operational Research 268: $852-864$.

Levine, E., E. Vaughan, and D. Nicholson. 2017. Strategic Resilience Assessment Guidelines. Portland: Mercy Corps.

O’Connell, D., N. Abel, N. Grigg, Y. Maru, J. Butler, A. Cowie, S. Stone-Jovicich et al. 2016. Designing Projects in a Rapidly Changing World: Guidelines for Embedding Resilience, Adaptation and Transformation into Sustainable Development Projects. Version 1.0. Washington: Global Environment Facility.

Resilience Alliance. 2010. Assessing Resilience in Social-Ecological Systems: Workbook for Practitioners. Version 2.0. www.resalliance.org/resilience-assessment.

\section{References}

Anderies, J.M., B.H. Walker, and A.P. Kinzig. 2006. 'Fifteen Weddings and a Funeral: Case Studies and Resilience-Based Management.' Ecology and Society 11(1): 21. www.ecologyandsociety.org/ vol11/iss1/art21.

Biggs, R., M. Schlüter, and M.L. Schoon, eds. 2015. Principles for Building Resilience: Sustaining Ecosystem Services. Cambridge: Cambridge University Press. 
Cowie, A., L.C.M. Waters, F. Garland, S.E. Orgill, A. Baumber, R. Cross, D. O'Connell, and G. Metternicht. 2019. 'Assessing Resilience to Underpin Implementation of Land Degradation Neutrality: A Case Study in the Rangelands of Western New South Wales, Australia.' Environmental Science and Policy 100: 37-46.

Daw, T.M., S. Coulthard, W.W.L. Cheung, K. Brown, C. Abunge, D. Galafassi, G.D. Peterson, T.R. McClanahan, J.O. Omukoto, and L. Munyi. 2015. 'Evaluating Taboo Trade-Offs in Ecosystem Services and Human Well-being.' Proceedings of the National Academy of Sciences 112(22): 6949-6954.

Douxchamps, S., L. Debevec, M. Giordano, and J. Barron. 2017. 'Monitoring and Evaluation of Climate Resilience for Agricultural Development - A Review of Currently Available Tools.' World Development Perspectives 5: 10-23. doi:10.1016/j.wdp.2017.02.001.

Elmqvist, T., E. Andersson, N. Frantzeskaki, T. McPhearson, P. Olsson, O. Gaffney, K. Takeuchi, and C. Folke. 2019. 'Sustainability and resilience for transformation in the urban century.' Nature Sustainability 2: 267-273. doi:10.1038/s41893-019-0250-1.

Enfors-Kautsky, E., L. Järnberg, A. Quinlan, and P. Ryan. 2018. Wayfinder: A Resilience Guide for Navigating Towards Sustainable Futures. GRAID Programme, Stockholm Resilience Centre. www.way finder.earth.

Folke, C. 2016. 'Resilience.' Ecology and Society 21(4): 44. doi:10.5751/ES-09088-210444.

Goffner, D., H. Sinare, and L.J. Gordon. 2019. 'The Great Green Wall for the Sahara and the Sahel Initiative as an Opportunity to Enhance Resilience in Sahelian Landscapes and Livelihoods.' Regional Environmental Change 19(5): 1417-1428.

Haider, J.L., A. Quinlan, and G.D. Peterson. 2012. 'Interacting Traps: Resilience Assessment of a Pasture Management System in Northern Afghanistan.' Planning Theory and Practice 13(2): 312-319.

Helfgott, A. 2018. 'Operationalising Systemic Resilience.' European Journal of Operational Research 268: 852-864. doi:10.1016/j.ejor.2017.11.056.

Herman, R.J., Y. Kushnir, A. Giannini, and M. Biasutti. 2018. 'Understanding Decadal and Interannual Variability in Rainfall over the Sahel.' AGU Fall Meeting Abstracts 21. https://ui.adsabs.harvard. edu/abs/2018AGUFM.A21F..07H/abstract.

Hermann, S., A.A. Diouf, and I. Sall. 2019. 'Beyond Productivity: Engaging Local Perspectives in Land Degradation Monitoring and Assessment.' Journal of Arid Environments 104002.

Huitric, M., G.D. Peterson, and J.C. Rocha. 2016. 'What Factors Build or Erode Resilience in the Arctic?' In Arctic Resilience Report. Stockholm: Stockholm Environment Institute and the Stockholm Resilience Centre. www.arctic-council.org/arr.

Lazzaroni, S., and N. Wagner. 2016. 'Misfortunes Never Come Singly: Structural Change, Multiple Shocks and Child Malnutrition in Rural Senegal.' Economics and Human Biology 23: 246-262.

Levine, E., E. Vaughan, and D. Nicholson. 2017. Strategic Resilience Assessment Guidelines. Portland: Mercy Corps. www.mercycorps.org/sites/default/files/STRESS-Guidelines-Resilience-MercyCorps-2017.pdf.

Malmborg, K. 2019. 'How on Earth: Operationalizing the Ecosystem Service Concept for Local Sustainability.' Licentiate diss., Stockholm University.

Maru, Y., D. O’Connell, N. Grigg, N. Abel, A. Cowie, S. Stone-Jovicich, J. Butler et al. 2017. Making 'Resilience', 'Adaptation' and 'Transformation' Real for the Design of Sustainable Development Projects: Piloting the Resilience, Adaptation Pathways and Transformation Assessment (RAPTA) Framework in Ethiopia. CSIRO, Australia.

Mercy Corps. 2018. Planting Seed of Resilience in Humanitarian Settings: Rapid Strategic Resilience Assessment Report for the Rohingya Crisis, Cox's Bazar, Bangladesh. www.mercycorps.org/sites/default/files/ MercyCorps-IOM_RapidStrategicResilienceAssessment_Report.pdf.

O’Connell, D., N. Abel, N. Grigg, Y. Maru, J. Butler, A. Cowie, S. Stone-Jovicich et al. 2016. Designing Projects in a Rapidly Changing World: Guidelines for Embedding Resilience, Adaptation and Transformation into Sustainable Development Projects. Version 1.0. Washington: Global Environment Facility.

ODI (Overseas Development Institute). 2016. 'Analysis of Resilience Measurement Frameworks and Approaches.' The Resilience Measurement, Evidence and Learning Community of Practice. www.measuring resilience.org.

OECD. 2014. Guidelines for resilience systems analysis. Paris: OECD Publishing.

Olsson, P., C. Folke, and T.P. Hughes. 2008. 'Navigating the Transition to Ecosystem-Based Management of the Great Barrier Reef, Australia.' Proceedings of the National Academy of Sciences 105(28): 9489-9494. 
Perrotton, A., A. Ka, and D. Goffner. 2019. 'WAYFINDER et Amélioration Collective de la Résilience dans le Département de Ranérou Ferlo: Rapport Stratégique.'

Pollard, S., H. Biggs, and D.R. du Toit. 2014. 'A Systemic Framework for Context-Based Decision Making in Natural Resource Management: Reflections on an Integrative Assessment of Water and Livelihood Security Outcomes Following Policy Reform in South Africa.' Ecology and Society 19(2): 63. doi:10.5751/ES-06312-190263.

Preiser, R., R. Biggs, A. de Vos, and C. Folke. 2018. 'Social-Ecological Systems as Complex Adaptive Systems: Organizing Principles for Advancing Research Methods and Approaches.' Ecology and Society 23(4): 46. doi:10.5751/ES-10558-230446.

Resilience Alliance (RA). 2010. Assessing Resilience in Social-Ecological Systems: Workbook for Practitioners. Version 2.0. www.resalliance.org/resilience-assessment.

Salomon, A.K., A.E. Quinlan, G.H. Pang, D.K. Okamoto, and L. Vazquez-Vera. 2019. 'Measuring Social-Ecological Resilience Reveals Opportunities for Transforming Environmental Governance.' Ecology and Society 24(3): 16. doi:10.5751/ES-11044-240316.

Sellberg, M.M., S. Borgstrom, A.V. Norstrom, and G.D. Peterson. 2017. 'Improving Participatory Resilience Assessment by Cross-fertilizing the Resilience Alliance and Transition Movement Approaches.' Ecology and Society 22(1): 28. doi:10.5751/ES-09051-220128.

Sellberg, M.M., A. Quinlan, R. Preiser, and G.D. Peterson. 2018a. 'How social-ecological resilience practice engages with complexity.' In Advancing Resilience Practice: Bridging Social-Ecological Resilience Theory and Sustainable Development Practice by M.M. Sellberg. PhD diss., Stockholm University.

Sellberg, M.M., P. Ryan, S.T. Borgstrom, A.V. Norstrom, and G.D. Peterson. 2018b. 'From Resilience Thinking to Resilience Planning: Lessons from Practice.' Journal of Environmental Management 217: 906-918. doi:10.1016/j.jenvman.2018.04.012.

Sellberg, M.M., C. Wilkinson, and G.D. Peterson. 2015. 'Resilience Assessment: A Useful Approach for Navigating Urban Sustainability Challenges.' Ecology and Society 20(1): 43. doi:10.575/ ES-07258-200143.

Sharifi, A. 2016. 'A critical Review of Selected Tools for Assessing Community Resilience.' Ecological Indicators 69: 629-647. doi:10.1016/j.ecolind.2016.05.023.

Steffen, W., Å. Persson, L. Deutsch, J. Zalasiewicz, M. Williams, K. Richardson, C. Crumley et. al. 2011. 'The Anthropocene: From Global Change to Planetary Stewardship.' Ambio 40(7): 739-761. doi:10.1007/s13280-011-0185-x.

UNDP. 2017. Community Based Resilience Analysis (CoBRA): Implementation Guidelines. Version 2. New York: UNDP.

Walker, B.H., N. Abel, J.M. Anderies, and P. Ryan. 2009. 'Resilience, Adaptability, and Transformability in the Goulburn-Broken Catchment, Australia.' Ecology and Society 14(1): 12. www. ecologyandsociety.org/vol14/iss1/art12.

Walker, B.H., S. Carpenter, J. Anderies, N. Abel, G. Cumming, M. Janssen, L. Lebel et al. 2002. 'Resilience Management in Social-Ecological Systems: A Working Hypothesis for a Participatory Approach.' Conservation Ecology 6(1): 14.

Walker, B.H., and D. Salt. 2012. Resilience Practice: Building Capacity to Absorb Disturbance and Maintain Function. Washington: Island Press.

Wilkinson, C. 2012. 'Social-Ecological Resilience: Insights and Issues for Planning Theory.' Planning Theory 11(2): 148-169. doi:10.1177/1473095211426274. 